\title{
Patient-reported outcomes for immediate identification of dental care needs
}

\author{
Pelin Güneri1*, Joel B. Epstein², Judith E. Raber-Durlacher³, \\ Hülya Çankaya ${ }^{1}$, Hayal Boyacıoğlu4, Andrei Barasch ${ }^{5}$
}

${ }^{1}$ Ege University School of Dentistry, Department of Oral and Maxillofacial

Radiology, Bornova 35100 Izmir, Turkey

${ }^{2}$ Samuel Oschin Comprehensive Cancer Institute, Cedars-Sinai Medical Center, Los Angeles, CA and Consulting Staff, Division of Otolaryngology and Head and Neck Surgery City of Hope National Medical Center, Duarte CA 8500 Whilshire Blvd, Suite 800 Beverly Hills, CA 90211, USA

${ }^{3}$ Department of Oral and Maxillofacial Surgery, Academic Medical Center Amsterdam and Department of Periodontology, Academic Centre for Dentistry Amsterdam, University of Amsterdam and VU University Amsterdam, Gustav Mahlerlaan 3004,1081 LA, Amsterdam, The Netherlands

${ }^{4}$ Ege University Faculty of Science, Department of Statistics, Bornova 35100 Izmir, Turkey

${ }^{5}$ Department of Dental Medicine, Winthrop-University Hospital 259 First Street, Mineola NY 11501, USA

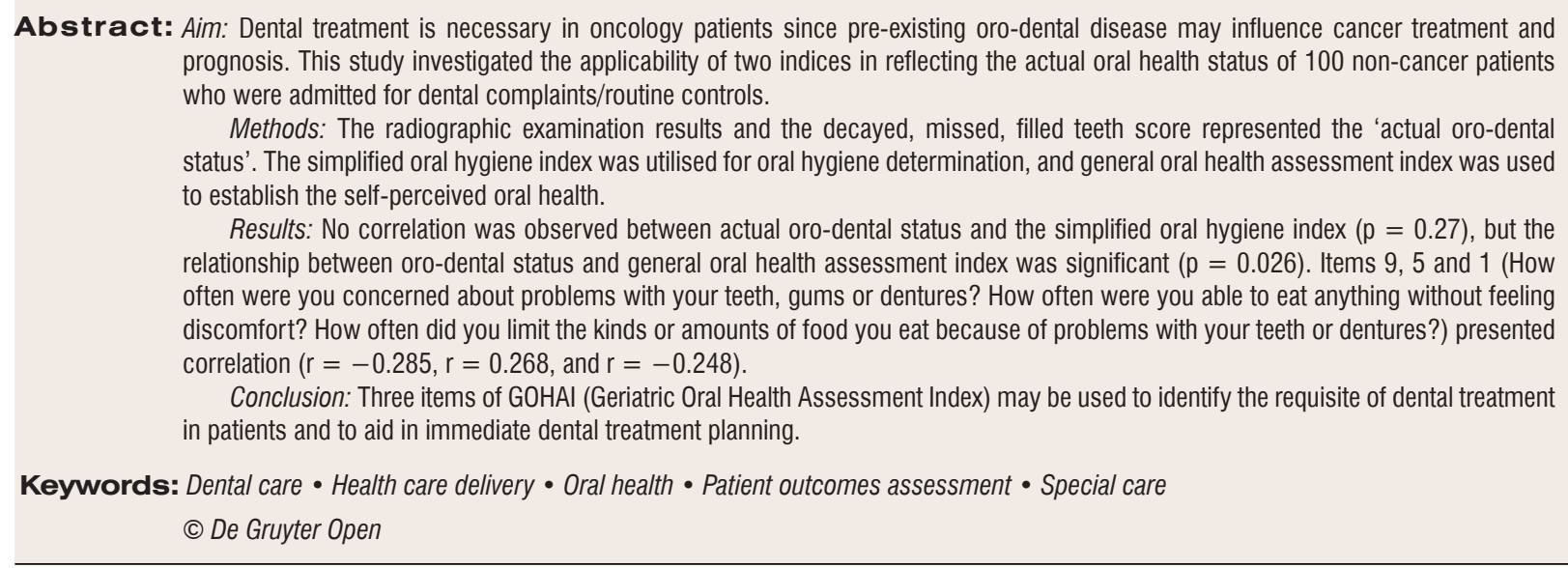

\section{Introduction}

Detection and management of potential sources of morbidity prior to initiation of specific consequential medical therapies (e.g. cytotoxic cancer treatment, solid organ/stem cell transplantation, and so on) is an important aspect of dental and oral care. Cancer patients hold a significant place among medically atrisk patients since acute and chronic side effects of cancer therapy such as mucositis, bacterial, viral and

*E-mail: peleen_2000@yahoo.com, pelinguneri@gmail.com

This study was presented as a poster at The 4th World Congress of International Association of Oral Oncology, 15-18 May 2013, Rhodes, Greece. 
fungal infections, salivary gland dysfunction, pain, taste change, dysphagia, soft tissue/bone necrosis and trismus are observed in oral cavity.(1-5). These may arise due to direct effects of treatment on the soft and hard oral tissues, or indirect damage through systemic toxicity (6). Oral complications diminish the quality of life (QOL) of oncology patient, impact the completion of planned treatment, and increase morbidity and possibly mortality (1, 2, 6-9). Additionally, preexisting dental and periodontal disease may exacerbate causing pain, local, regional and systemic infection in the setting of malignant disease, and these conditions may not be effectively managed when the patient is medically compromised. Nevertheless, the probability of symptomatic infection during cytotoxic treatment may be reduced by approximately one-third (250 versus $318 / 1000)$ in haematopoietic stem cell transplantation (HSCT) patients when dental treatment is provided prior to transplantation (10). Schuurhuis et al. showed in head and neck cancer (HNC) patients that if dental foci of infection are treated prior to radiation therapy, the risk of post-treatment osteoradionecrosis is reduced by half compared to those patients in whom dental foci are not successfully treated (11). Hence, any oro-dental problems should be assessed prior to cytotoxic regimen $(10,12-15)$ and their treatment should be completed as quickly as possible so that cancer therapy can begin without any delay.

The goal of this study is to investigate whether two common indices [the simplified oral hygiene index (OHI-S) and the geriatric/general oral health assessment index (GOHAI)] reflect the oral health status in a general, non-cancer patient population in an outpatient dental clinic as a patient reported outcome (PRO) tool that may facilitate identification of dental treatment needs in cancer patients.

\section{Materials and Methods}

We recruited 100 dental patients who had been admitted to Ege University School of Dentistry, Department of Oral and Maxillofacial Radiology for either dental complaints or regular annual dental check-ups, and who required panoramic radiographs during their examinations. None of these patients had a diagnosis and/or were under treatment of malignant disease. The study has been administered in full accordance with ethical principles of the World Medical Association Declaration of Helsinki and informed consents were obtained prior to enrolment. Edentulous patients and those who did not need panoramic radiographs were excluded from the study. Two experienced, calibrated dental practitioners
(HÇ, PG) performed both the interviews and the clinicalradiographical examinations of the patients.

Clinical examination was performed with the patient seated on a dental chair under standard conditions (16). Clinically detected carious lesions were recorded (CR). For each patient, a panoramic radiograph was obtained using standard radiographic equipment (Trophy Radiologie, Croissy-Beabourg, France) and protocols. Carious lesions identified on the films were included in the DMFT score and all (clinically and/or radiographically detected) decayed, filled and missing teeth were recorded as CR+DMFT, representing the 'actual oro-dental status' of the patients.

For oral hygiene determination, OHI-S was applied for present teeth (http://www.mah.se/CAPP/Methods-andIndices/Oral-Hygiene-Indices/Simplified-Oral-HygieneIndex--OHI-S, accessed on 16.09. 2011): simplified debris index (DI-S) and simplified calculus index (CI-S) with scores ranging from 0 to 3 were recorded. For each individual, the debris and calculus scores were totalled and divided by the number of surfaces scored. At least two of the six possible tooth surfaces were examined for an individual score to be calculated. OHI-S scores ranged between 0 and 6 , the latter representing the worst oral hygiene (Figure 1).

The patients responded to the GOHAI questionnaire prior to receiving dental treatment. In GOHAI, physical functions such as eating, speaking, and swallowing (items 1-4), and psychosocial functions (satisfaction with appearance, worries or concerns about oral health, inhibition of social contacts due to these concerns) were investigated (items 6, 7, 9-11). Additionally, the level of pain/discomfort during eating, and sensitivity to hot, cold or sweets were established (items 5, 8, and 12) (17). Of the 12 items, 3 had positive (items 3, 5 and 7) and 9 had negative outcomes; that is, higher scores provided for items 3, 5 and 7 indicated a better oral health perception, whereas lower scores given for the other items revealed

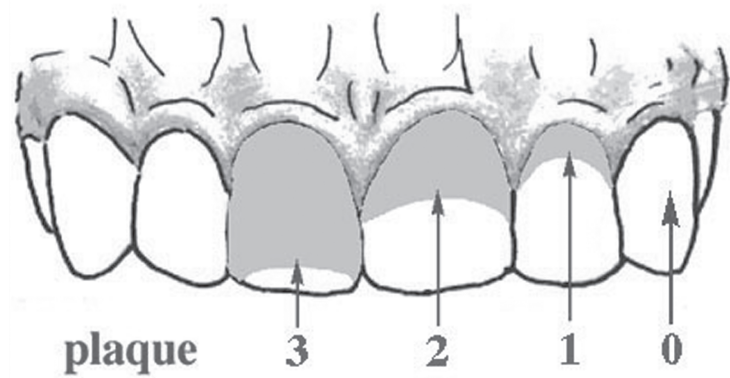

Figure 1: Diagram explaining OHI-S index. (http://www.mah.se/ CAPP/Methods-and-Indices/Oral-Hygiene-Indices/ Simplified-Oral-Hygiene-Index--OHI-S, accessed on 16.09. 2011) 
Table 1. The items of GOHAl that investigate pain/discomfort, psychosocial and functional problems of patients.

\begin{tabular}{|c|c|c|c|c|c|}
\hline $\begin{array}{l}\text { GOHAl } \\
\text { (Please identify the followings according to your last } \\
3 \text { months experiences) }\end{array}$ & Always & Often & Sometimes & Seldom & Never \\
\hline \multicolumn{6}{|l|}{$\begin{array}{l}\text { 1. How often did you limit the kinds or amounts of food you eat because } \\
\text { of problems with your teeth or dentures? (function) }\end{array}$} \\
\hline \multicolumn{6}{|l|}{$\begin{array}{l}\text { 2. How often did you have trouble biting or chewing any kinds of food, } \\
\text { such as firm meat or apples? (function) }\end{array}$} \\
\hline \multicolumn{6}{|l|}{$\begin{array}{l}\text { 3. How often were you able to swallow comfortably? (function) positive } \\
\text { outcome }\end{array}$} \\
\hline \multicolumn{6}{|l|}{$\begin{array}{l}\text { 4. How often have your teeth or dentures prevented you from speaking } \\
\text { the way you wanted? (function) }\end{array}$} \\
\hline \multicolumn{6}{|l|}{$\begin{array}{l}\text { 5. How often were you able to eat anything without feeling discomfort? } \\
\text { (function/pain/discomfort) positive outcome }\end{array}$} \\
\hline \multicolumn{6}{|l|}{$\begin{array}{l}\text { 6. How often did you limit contacts with people because of the condition } \\
\text { of your teeth and gums, or dentures? (psychosocial) }\end{array}$} \\
\hline \multicolumn{6}{|l|}{$\begin{array}{l}\text { 7. How often were you pleased or happy with the looks of your teeth and } \\
\text { gums, or dentures? (psychosocial) positive outcome }\end{array}$} \\
\hline \multicolumn{6}{|l|}{$\begin{array}{l}\text { 8. How often did you use medication to relieve pain or discomfort from } \\
\text { around your mouth? (function/pain/discomfort) }\end{array}$} \\
\hline \multicolumn{6}{|l|}{$\begin{array}{l}\text { 9. How often were you worried or concerned about problems with your } \\
\text { teeth, gums, or dentures? (psychosocial) }\end{array}$} \\
\hline \multicolumn{6}{|l|}{$\begin{array}{l}\text { 10. How often did you feel nervous or self-conscious because of } \\
\text { problems with your teeth, gums, or dentures? (psychosocial) }\end{array}$} \\
\hline \multicolumn{6}{|l|}{$\begin{array}{l}\text { 11. How often did you feel uncomfortable eating in front of people } \\
\text { because of problems with your teeth or dentures? (psychosocial) }\end{array}$} \\
\hline $\begin{array}{l}\text { 12. How often were your teeth or gums sensitive to hot, cold, or } \\
\text { sweets?(function/pain/discomfort) }\end{array}$ & & & & & \\
\hline
\end{tabular}

GOHAl: geriatric/general oral health assessment index

a better oral health recognition (18). Each item was marked and scored in a Likert-type scale as 'always = 1 , often (once a week) $=2$, sometimes (once a month) $=3$, seldom (once or twice in three months) $=4$, never = 5' $(16,19)$ (Table 1). For each subject, the scores for positive outcomes were reversed in order to provide a score where the directions of all answers would be the same. The item scores were totalled (Add-GOHAI) and recorded within the range of 12 (minimum) to 60 (maximum); higher values indicating a better selfperception of oral health $(16,19-23)$. A score of 57-60 was regarded as 'high', corresponding to a satisfactory oral QOL, whereas a score of 51-56 represented an average and a score of $\leq 50$ revealed a low/poor oral QOL (19).

In order to examine the correlation between CR+DMFT (actual dental status), OHI-S and GOHAI, data were analysed using Spearman's rho correlation test. All statistical analyses were performed on SPSS 15 (SPSS, Chicago, IL). P was set as 0.05 .
Table 2. The mean, minimum, maximum values and standard deviations of the indices observed in 100 patients.

\begin{tabular}{c|ccc}
\hline & Total GOHAl & OHI-S & CR+DMFT \\
\hline \hline mean & 40.64 & 0.97 & 7.12 \\
SD & 6.47 & 0.74 & 5.09 \\
min. & 23 & 0.00 & 0.00 \\
max. & 52 & 3.00 & 28.00 \\
\hline
\end{tabular}

GOHAl: geriatric/general oral health assessment index

OHI-S: simplified oral hygiene index

\section{Results}

Total GOHAI scores for the 100 patients ranged between 23 and 52 (mean $=40.64, \mathrm{SD}=6.47$ ). Four patients achieved a score of 51 and over, indicating an 'average' oral QOL. All other patients had scores consistent with 'poor' oral QOL. 
The mean OHI-S score was $0.97 \pm 0.74$, whereas mean CR+DMFT was $7.12 \pm 5.09$ (Table 2).

Statistical analysis revealed no significant correlation between CR+DMFT and OHI-S ( $p=0.27$ ). However, a significant relationship was observed between CR+DMFT and GOHAl scores ( $p=0.026, r=-0.276)$.

Using Spearman's rho correlation analysis, the association between questions of GOHAl and CR+DMFT was investigated in order to identify the items that better reflected the oro-dental status of the patients. The results showed that, out of 12 questions included in GOHAI, 9 were not significantly related to the CR+DMFT scores; the other 3 questions revealed significant association (Table 3). The most significantly correlated question was item 9 (How often were you worried or concerned about problems with your teeth, gums, or dentures?), and it had a strong negative correlation with dental status of the patients $(r=-0.285, p=0.004<0.05)$. GOHAl items 5 (How often were you able to eat anything without feeling discomfort?) and 1 (How often did you limit the kinds or amounts of food you eat because of problems with your teeth or dentures?) had a weaker positive correlation with the dental health of the patients $(r=$ $0.268, p=0.007<0.05$ and $r=-0.248, p=0.013<$ 0.05 , respectively).

\section{Discussion}

In oncology, dental examination and treatment planning requires consultation and care that are integrated with the cancer treatment team (24). Development of a PRO form that reliably identifies a patient's dental needs prior to medical management of malignancy may have utility in the care of medically compromised and/or complex patients. Another objective of developing PROs may be to provide insight in the relation between oral health and complications during therapy in large populations of cancer patients. This study explored the correlation of OHI-S and GOHAl to the actual oro-dental status in a group of consecutive patients seen in a dental clinic, in order to investigate whether these indices would be useful to identify appropriate items for development of an instrument that can be used for identification of dental care needs in cancer patients.

Patient's dental status, oral hygiene, past dental care, periodontal and soft tissues status must be assessed using appropriate diagnostic tools in order to develop an adequate dental treatment plan that includes oral hygiene instruction, extractions and a schedule for recalls, preventive programmes and follow-up of the patient's progress $(2,6,24-27)$ (Table 4). This is particularly true for medically complex oncology
Table 3. The correspondence of the questions of GOHAl with CR+DMFT results, starting with the most correlated question and ending with the least related one.

\begin{tabular}{c|cc}
\hline GOHAl item & $\mathbf{r}$ & $\mathbf{p}$ \\
\hline \hline 9 & -0.285 & $0.004<0.05$ \\
5 & 0.268 & $0.007<0.05$ \\
1 & -0.248 & $0.013<0.05$ \\
2 & -0.18 & 0.073 \\
8 & -0.151 & 0.133 \\
11 & -0.148 & 0.141 \\
10 & -0.133 & 0.186 \\
7 & -0.085 & 0.402 \\
12 & -0.082 & 0.417 \\
6 & -0.053 & 0.597 \\
3 & -0.022 & 0.83 \\
4 & 0.137 & 0.174 \\
\hline
\end{tabular}

GOHAl: geriatric/general oral health assessment index

populations. Unfortunately, few cancer centres have integrated experienced dental practitioners who examine the patients and provide oral care prior to and throughout cancer continuum; even fewer have dental treatment service on site, $(1,2,26)$ and most have not employed an oral/dental assessment instrument (2). Therefore, initial and ongoing assessment of the oral cavity using validated instruments that include both patient self-report and professional examination (27) and integrated dental and medical care are necessary for the best treatment planning and outcomes.

A number of indices may be utilised to assess the dental needs of patients: the DMFT index is a means to obtain an estimation of dental disease burden and is currently suggested as the principal oral health index by the World Health Organization (WHO) $(6,28)$. However, this index only describes the past and current caries history and dental care, and does not document if the cavity is threatening the pulp and/or leading to abscess formation (6). Furthermore, other significant oral conditions, including periodontal disease, are not considered in this index. Periodontal disease and the general oral condition (e.g.: mucosa, saliva) and the risk of infection from an oral source are not identified. Periodontal attachment loss may be a good predictor of root caries incidence (29), but it is not assessed with the DMFT index.

The OHI-S was first described by Greene and Vermillion in order to assess the oral hygiene of patients 
Table 4. An adequate dental assessment plan for patients who are scheduled for cancer.

\begin{tabular}{c}
\hline Pre-cancer treatment dental assessment \\
Definitive diagnosis \\
Medical history \\
Dental history/past dental care/dental hygiene status \\
Complete dental exam (mucosal dental exam, periodontal, \\
temporomandibular joint (TMJ) \\
Radiographic survey (panoramic and adjunctive periapicals or full- \\
mouth periapicals) \\
Saliva tests (unstimulated and stimulated saliva volumes) \\
Adjunctive tests as indicated (e.g. pulp tests, cultures) \\
Prognosis for cure vs. palliation \\
radiation fields/chemotherapy)
\end{tabular}

in epidemiological surveys (30). It is used to record the oral hygiene profile of the patient at the time of evaluation $(31,32)$. GOHAI is a patient-reported measure of oral health status that contains 12 items to establish 'patient reported oral functional problems' and 'psychosocial impacts associated with oral diseases.' It is also intended for use in the assessment of the effectiveness of dental treatment on oral health-related quality of life $(16,17$, 33-38).

As there is considerable variability in dental services available to patients undergoing cancer therapy and other advanced medical care such as organ transplantation, utilisation of a simple, self-report to identify the urgent oral/dental needs of the patients prior to cancer therapy may facilitate recognition, diagnosis and prompt intervention.

This study assessed the potential utility of OHI-S and GOHAl as a guide for developing a PRO tool that identifies the risk for further complications and the need for prompt oro-dental care. In the literature, GOHAI scores are calculated in two different ways: The additive score (ADD-GOHAI) is the sum score that is determined after items 3, 5 and 7 are inverted, and ranges from 12 to 60 (high scores indicate few problems). The simple count score (SC-GOHAI) is a count of the items with the responses 'sometimes', 'often' and 'always' and ranges from 0 to 12 (12 indicates poor oral health) (39-42). In the present study, we utilised the first approach and calculated the sum of the scores after reversing the items with positive outcome, so that all answers would have the same direction, as done in other studies (16, $21,23,39,41,43,44)$.
The patients with lower GOHAI scores, that is, poorer oral health-related $\mathrm{QOL}$, reported themselves as having more life stress, and worse satisfaction and morale (39). However, Sanchez Garcia et al. stated that the missing and filled components of the DMFT index had a low correlation with the GOHAl score, and the elderly patients mostly based their oral health perceptions on functional concerns (16).

Current screening indices are limited in detecting active dental disease, including caries, dental abscess and periodontal status $(45,46)$. In our study, OHI-S was not correlated with CR+DMFT, but 3 out of 12 items of GOHAI were associated with the objective oro-dental status of the patients. These questions have potential to be included in a new PRO form.

A major limitation of this study is that none of the indicators that identify the presence of symptomatic and advanced dental processes that may present a risk in cancer patients, and medically complex patients such as abscess, deep caries threatening the pulp, impacted teeth, and advanced periodontitis were included in these indices. Therefore, these items that may be considered among the indicators of urgency of dental treatment should be contained in the planned PRO tool. Additionally, some confounding variables such as gender, level of education and income of the elderly and cognitive variations may influence the GOHAI score (16); these factors were not studied here. Also, panoramic radiographs would not accurately diagnose the carious lesions, and periapical radiographic evaluation would be more accurate; but, full-mouth periapical screening is not a procedure that is required frequently in a dental clinic and was not utilised as radiographic assessment tool in our patient sample.

\section{Conclusions}

This study suggests that in addition to parameters that investigate the presence of infection, including dental abscess, gingivitis, periodontitis and pericoronitis, three items of GOHAl may be utilised in identifying dental conditions that should be addressed prior to complex medical care or cancer therapy. Unique therapy, including head and neck and oral cancer, and new therapies, including targetted therapy and immunotherapy, present additional and unique considerations.

This is a first step in validating the self-reported oral condition aimed at facilitating screening procedures in medically compromised or oncology patients. Future studies should be directed to develop specific questions directed to evaluate the periodontal condition. With this approach, prompt initiation of appropriate dental therapy 
before beginning cancer treatment not only reduces the oral complications of radiotherapy/chemotherapy and enhances the QOL of cancer patients, but also decreases the morbidity and mortality that may arise due to severe oral complication-related outcomes.

\section{References}

[1] Barker GJ, Epstein JB, Williams KB, Gorsky $M$, Raber-Durlacher JE. Current practice and knowledge of oral care for cancer patients: a survey of supportive health care providers. Support Care Cancer 2005;13:32-41.

[2] Epstein JB, Parker IR, Epstein MS, Gupta A, Kutis S, Witkowski DM. A survey of national cancer institute-designated comprehensive cancer centers' oral health supportive care practices and resources in the USA. Support Care Cancer 2007;15:357-62.

[3] Barasch A, Epstein JB. Management of cancer therapy-induced oral mucositis. Dermatolther 2011;24: 424-31.

[4] WattersAL, Epstein JB,AgulnikM. Oral complications of targeted cancer therapies: a narrative literature review. Oral Oncol 2011;47:441-8.

[5] Roe JWG, Carding PN, Rhys-Evans PH, Newbold $\mathrm{KL}$, Harrington $\mathrm{KJ}$, Nutting $\mathrm{CM}$. Assessment and management of dysphagia in patients with head and neck cancer who receive radiotherapy in the United Kingdom -A web-based survey. Oral Oncol 2012;48:343-8.

[6] Hong CHL, Napeñas JJ, Hodgson BD, et al. A systematic review of dental disease in patients undergoing cancer therapy. Support Care Cancer 2010;18:1007-21.

[7] Bensadoun RJ, Patton LL, Lalla RV, Epstein JB. Oropharyngeal candidiasis in head and neck cancer patients treated with radiation: Update 2011. Support Care Cancer 2011;19:737-44.

[8] Mosel DD, Bauer RL, Lynch DP, Hwang ST. Oral complications in the treatment of cancer patients. Oral Dis 2011;17:550-9.

[9] Nicolatou-Galitis O, Sarri T, Bowen J, et al. Systematic review of amifostine for the management of oral mucositis in cancer patients. Support Care Cancer 2013; 21:357-64.

[10] Elad S, Thierer T, Bitan M, Shapira MY, Meyerowitz C. A decision analysis: the dental management of patients prior to hematology cytotoxic therapy or hematopoietic stem cell transplantation. Oral Oncol 2008;44:37-42.

[11] Schuurhuis JM, Stokman MA, Roodenburg JL, et al. Efficacy of routine pre-radiation dental screening

\section{Acknowledgement}

The authors have no conflict of interest.

and dental follow-up in head and neck oncology patients on intermediate and late radiation effects. A retrospective evaluation. Radiother Oncol 2011;101:403-9.

[12] Epstein JB, Wong FLW, Stevenson-Moore P. Osteoradionecrosis: clinical experience and a proposal for classification. J Oral Maxillofac Surg 1987;45:104-10.

[13] Epstein JB, Stevenson-Moore P, Jackson SM, Mohammed JH, Spinelli JJ. Prevention of oral mucositis in radiation therapy: a controlled study with benzydamine hydrochloride rinse. Int J Radiat Oncol Biol Phys 1989;16:1571-5.

[14] Epstein JB, Van Der Meij E, Mckenzie M, Wong F, Lepawsky M, Stevenson-Moore P. Post-radiation osteonecrosis of the mandible. Oral Surg Oral Med Oral Pathol Oral Radiol Endod 1997;83:657-62.

[15] Pagare SS, Khosa SK. Osteoradionecrosis. Int J Head Neck Surg 2011;2:27-32.

[16] Sánchez-García S, Heredia-Ponce E, JuárezCedillo $\mathrm{T}$, et al. Psychometric properties of the general oral health assessment index (GOHAI) and dental status of an elderly Mexican population. J Public Health Dent 2010;70:300-7.

[17] Kressin NR, Atchison KA, Miller DR. Comparing the impact of oral disease in two populations of older adults: application of the geriatric oral health assessment index. J Public Health Dent 1997;57:224-32.

[18] Franchignoni M, Giordano A, Levrini L, Ferriero G, Franchignoni F. Rasch analysis of the geriatric oral health assessment index. Eur J Oral Sci 2010;118:278-83.

[19] Nicolas E, Veyrune JL, Lassauzay C. A six-month assessment of oral health-related quality of life of complete denture wearers using denture adhesive: a pilot study. J Prosthodont 2010;19:443-8.

[20] Mcmillan AS, Tsang CS, Wong MC, Kam AY. Efficacy of a novel lubricating system in the management of radiotherapy-related xerostomia. Oral Oncol 2006;42:842-8.

[21] Atieh MA. Arabic version of the Geriatric Oral Health Assessment Index. Gerodontology 2008;25:34-41.

[22] Daradkeh S, Khader YS. Translation and 
validation of the arabic version of the geriatric oral health assessment index (GOHAl). J Oral Sci 2008;50:453-9.

[23] Shigli K, Hebbal M. Assessment of changes in oral health-related quality of life among patients with complete denture before and 1 month postinsertion using geriatric oral health assessment index. Gerodontology 2010;27:167-73.

[24] Mackie AM, Epstein JB, Wu JS, Stevenson-Moore P. Nasopharyngeal carcinoma: the role of the dentist in assessment, early diagnosis and care before and after cancer therapy. Oral Oncol 2000;36:397-403.

[25] Raber-Durlacher JE, Epstein JB, Raber J, Van Dissel JT, Van Winkelhoff AJ, Guiot HF, Van Der Velden U. Periodontal infection in cancer patients treated with high-dose chemotherapy. Support Care Cancer 2002;10:466-73.

[26] Epstein JB, Parker IR, Epstein MS, StevensonMoore P. Cancer-related oral health care services and resources: a survey of oral and dental care in Canadian cancer centres. J Can Dent Assoc 2004;70:302-4.

[27] Keefe DM, Schubert MM, Elting LS, et al. Updated clinical practice guidelines for the prevention and treatment of mucositis. Cancer 2007;109:820-31.

[28] Berg-Beckhoff G, Kutschmann M, Bardehle D. Methodological considerations concerning the development of oral dental erosion indexes: literature survey, validity and reliability. Clin Oral Invest 2008;12(Suppl1):S51-8.

[29] Ritter AV, Shugars DA, Bader JD. Root caries risk indicators: a systematic review of risk models. Community Dent Oral Epidemiol 2010;38:383-97.

[30] U.S. Department Of Health Education, And Welfare, Public Health Service, Health Services And Mental Health Administration, National Center For Health Statistics June 1972. Periodontal Disease And Oral Hygiene Among Children: United States. Vital And Health Statistics-Series 11-No. 117. Dhew Publication No. (Hsm) 72-1060. Library 'Of Congress Gatazog Card Number 72-190009

[31] Angelillo IF, Nobile CG, Pavia M. Oral health status and treatment needs in immigrants and refugees in Italy. Eur J Epidemiol 1996;12:359-65.

[32] Wandera M, Astrom AN, Okullo I, Tumwine JK. Determinants of periodontal health in pregnant women and association with infants' anthropometric status: a prospective cohort study from Eastern Uganda. BMC Pregnancy Childbirth 2012;12:90.

[33] Atchison KA, Der-Martirosian C, Gift HC. Components of self-reported oral health and general health in racial and ethnic groups. J Public Health Dent 1998;58:301-8.
[34] Locker D, Allen F. What do measures of 'Oral HealthRelated Quality Of Life' measure? Community Dent Oral Epidemiol 2007;35:401-11.

[35] Ozcelik O, Haytac MC, Seydaoglu G. Immediate post-operative effects of different periodontal treatment modalities on oral health-related quality of life: a randomized clinical trial. J Clin Periodontol 2007;34:788-96.

[36] Guzeldemir E, Toygar HU, Tasdelen B, Torun D. Oral health-related quality of life and periodontal health status in patients undergoing hemodialysis. J Am Dent Assoc 2009;140:1283-93.

[37] Piuvezam G, De Lima KC. Self-perceived oral health status in institutionalized elderly in Brazil. Arch Gerontol Geriatr 2012;55:5-11.

[38] Zuluaga DJ, Montoya JA, Contreras Cl, Herrera RR. Association between oral health, cognitive impairment and oral health-related quality of life. Gerodontology 2012;29:E667-73.

[39] Locker D, Matear D, Stephens M, Lawrence H, Payne B. Comparison of the GOHAl and OHIP-14 as measures of the oral health-related quality of life of the elderly. Community Dent Oral Epidemiol 2001;29:373-81.

[40] Jones JA, Kressin NR, Kazis LE, Miller DR, lii AS, Lee A, Garcia RI. Oral conditions and quality of life. J Ambul Care Manage 2006;29:167-81.

[41] Hassel AJ, Rolko C, Koke U, Leisen J, Rammelsberg P. A German version of the GOHAl. Community Dent Oral Epidemiol 2008;36:34-42.

[42] Abud MC, Dos Santos JF, Da Cunha Vde P, Marchini L. TMD and GOHAI indices of Brazilian institutionalised and community-dwelling elderly. Gerodontology 2009;26:34-9.

[43] Tsakos G, Sheiham A, lliffe S, Kharicha K, Harari $D$, Swift CG, Gillman G, Stuck AE. The impact of educational level on oral health-related quality of life in older people in London. Eur J Oral Sci 2009;117:286-92.

[44] Ikebe K, Hazeyama T, Enoki K, Murai S, Okada T, Kagawa R, Matsuda K, Maeda Y. Comparison of GOHAl and OHIP-14 measures in relation to objective values of oral function in elderly Japanese. Community Dent Oral Epidemiol 2012;40:406-14.

[45] Tanaka MH, Bocardi K, Kishimoto YK, Jacques P, Spolidorio DMP, Giro EMA. DMFT index assessment and microbiological analysis of Streptococcus Mutans in institutionalized patients with special needs. Braz J Oral Sci 2009;8:9-13.

[46] Benzian H, Monse B, Heinrich-Weltziehn R, Holmgren C, Helderman WVP. Dental indices must not be cast in stone. Int Dent J 2011;61:238-40. 